\title{
Disgust Emotion and Obsessive-Compulsive Symptoms in an Iranian Clinical Sample
}

\author{
Giti Shams $^{1 *}$, Leyla Janani², Irena Milosevic ${ }^{3}$, Elham Foroughi ${ }^{4}$ \\ ${ }^{1}$ Department of Psychiatry, Roozbeh Hospital, Tehran University of Medical Sciences (TUMS), Tehran, Iran \\ ${ }^{2}$ Department of Biostatistics, School of Public Heaths, Iran University of Medical Sciences (IUMS), Tehran, Iran \\ ${ }^{3}$ Department of Psychology, Concordia University, Montreal, Canada \\ ${ }^{4}$ Department of Psychology, School of Behavioral Science, University of Melbourne, Melbourne, Australia \\ Email: ${ }^{*}$ shamsgit@tums.ac.ir
}

Received 9 June 2015; accepted 18 October 2015; published 21 October 2015

Copyright (C) 2015 by authors and Scientific Research Publishing Inc.

This work is licensed under the Creative Commons Attribution International License (CC BY). http://creativecommons.org/licenses/by/4.0/

c) (i) Open Access

\section{Abstract}

A growing body of research has revealed robust associations between disgust and obsessivecompulsive disorder (OCD) symptoms. The present study aimed to understand if particular disgust domains are more closely associated with OC symptoms subscales, especially contamination and washing. A sample of $60 \mathrm{OCD}$ patients from an outpatient Iranian psychiatric clinic completed self-report questionnaires including the Disgust Scale-Revised (DS-R), the Obsessive-Compulsive Inventory-Revised (OCI-R) and the Padua inventory-Washington State University revision (PIWSUR). The results indicated correlations between the total, core and contamination subscales of the DS-R together with the OCI-R total score as well as with the PI-WSUR total score. However, no correlation was found between these inventories and the DS-R animal reminder subscale. The DS-R total score also correlated with the washing and checking subscales of the OCI-R and with the contamination obsessions and washing and checking compulsions of the PI-WSUR. The relationship between disgust and demographic characteristics showed that the DS-R total, core and contamination scores were significantly higher for women and married subjects, and that the animal reminder subscale score was significantly higher for women than men. Although symptoms presentation, risk factors, and outcomes may vary cross-culturally, very little is known about disgust emotion as an OCD symptom in Iranian and eastern cultures. Additional work is needed to better understand these symptoms in other eastern cultures.

\section{Keywords}

OCD, Disgust Emotion, Persian and Eastern Cultures

\footnotetext{
${ }^{*}$ Corresponding author.
} 


\section{Introduction}

Disgust is an emotion typically associated with things that are considered dirty, unappetizing, contagious, or otherwise offensive (Olatunji, Sawchuk, Arrindel, \& Lohr, 2005). It has been hypothesized that individuals with obsessive-compulsive disorder (OCD) will tend to have higher level of disgust sensitivity (Rachman, 2004) and that disgust would have an evolutionary function to prevent contamination and disease (Izard, 1993). However, theoretical extensions have proposed that disgust may contribute to the etiology and maintenance of OCD-related contaminations and washing compulsions (e.g. Phillips, Senior, Fahy, \& David, 1998). Several descriptive researches highlight a positive association between self-report measures of disgust and OCD-related contamination concerns (Moretz \& McKay, 2008; Olatunji et al., 2010; Sawchuk, Lohr, Tolin, Lee, \& Kleinknecht, 2000). One of the most common and debilitating features of OCD is characterized by contamination fears (Rachman, 2004; Rasmussen \& Eisen, 1992) and it is now well established that disgust experience is associated with an increased severity of OCD with contamination fears symptomatology (Cisler, Olatunji, Sawchuk, \& Lohr, 2008; Mancini, Gragnani, \& D’Olimpio, 2001; Olatunji, Sawchuk, Lohr, \& de Jong, 2004; Olatunji et al., 2007; Olatunji et al., 2010; Tolin, Woods, \& Abramowitz, 2006).

Recent investigations are interested to examine disgust responses among clinical and subclinical OCD subjects. For example, Mancini et al. (2001) found a significant positive relationship between disgust and OC symptoms in a non-clinical sample. Washing and checking behaviors were significantly and uniquely predicted by disgust sensitivity for both men and women. However, these authors did not find a strong link between disgust sensitivity and other OCD subscales, e.g. impulses and rumination among female participants. Other recent studies have found significant associations between disgust proneness and a range of OCD symptoms such as hoarding, neutralizing, and ordering (Olatunj et al., 2010; Olatunji, Cisler, McKay, \& Phillips, 2010). On the contrary, other investigations indicated less satisfying reasons that might suggest an association between disgust and other subtypes of OCD and those investigations suggested that hoarding might be associated with reduced disgust-sensitivity (Thorpe, Patel, \& Simonds, 2003). Nevertheless, the evidence that there is a link between disgust and these other OCD subtypes is tenuous. Although Schienle, Stark, Walter, \& Vaitl (2003) found disgust-sensitivity to be associated with all four of the MOCI subscales (washing, checking, doubting and slowness), Muris et al. (2000) reported that, aside from washing, the only MOCI subscale that was significantly associated with disgust was the slowness scale which, in any case, was weak. Less robust results were reported by Tolin et al. (2006) who found that only disgust-specific hygienic concerns retained its relationship with OCD washing. In a study examining disgust in a clinical sample, Woody \& Tolin (2002) found out that OCD washers report significantly higher disgust than non-anxious controls, and marginally higher disgust sensitivity than did non-washing OCD subjects. However, OCD washers did not exhibit greater levels of disgust sensitivity than did patients with social phobia. In a study of Olatunji et al. (2007), disgust factors were significantly related scores of contamination fears and obsessive-compulsive symptoms (particularly washing, ordering and checking symptoms).

On the other hand, from a cultural point of view, Haidt, McCauley, \& Rozin (1994) found out that when compared to European American participants, African Americans scored significantly higher on the Disgust Scale. Tolin et al. (2006) also found that nonwhites (mostly African Americans) scored significantly higher than whites did on the Disgust Scale.

Evidence in western culture for the relationship between disgust sensitivity and OCD has been a mix; based on prior findings, the results indicated a strong relationship between disgust and washing in OCD but this relationship was weak in other subscales. Moreover very little is known about the construct of disgust and how it relates to contamination concerns and OCD. Overall, medium strength correlations have been reported between disgust and various OCD subscales (Mancini et al., 2001; Muris et al., 2000; Olatunji et al., 2004; Sawchuk et al., 2000; Schienle et al., 2003; Thorpe et al., 2003). In addition, almost all these studies were performed in western countries and in absence of eastern cultures (e.g. Iranian culture). Therefore, it is pertinent to question the relationship between disgust and OCD in non-western countries or cultures. In fact, Iran has a long history of intercultural mixing and might be considered as an in-between country betwixt east and west. Mostly, Iranian culture is familiar to west civilization and lifestyle.

The present study aimed to extend previous research investigating the link between the domains of the disgust emotion and the OCD subscales and it has the particularity to measure it in a non-western culture i.e. an OCD Iranian out-patients population. We used three valid, well know and largely used self-report questionnaires: the 
Disgust Scale-Revised (DS-R; Haidt, 1994), the Obsessive-Compulsive Inventory-Revised (OCI-R; Foa et al., 2002) and the Padua inventory-Washington State University revision (PI-WSUR; Burns, Keortge, Formea, \& Sternberger, 1996). The hypothesis is that disgust emotion is substantially related to certain OC subscales (e.g. contamination and washing subscale) but not to all of them. Another aim of this study is to understand the relationship between disgust sensitivity and demographic characteristics such as age, sex, marital status, education, socio-economic and occupation.

\section{Methods}

\subsection{Participants}

60 OCD patients were recruited from a CBT outpatient clinic in Roozbeh Hospital (Tehran University of Medical Sciences). In the first step, a diagnosis of OCD based on a clinical interview has been established by a psychiatrist using criteria of the 4th edition of the Diagnostic and statistical manual of mental disorders (DSMIV-TR; American Psychiatric Association, 2000). In a second step, a clinical psychologist interviewed the patient using a CBT based interview for case conceptualization. Inclusion criteria were: a primary diagnosis of OCD and no evidence of current substance abuse, current or past schizophrenia, bipolar disorder or organic mental disorder.

\subsection{Measures}

1) The Disgust Scale-Revised (DS-R; Haidt, 1994) modified by Olatunji et al. (2007) is a 25 item measure of disgust sensitivity across three dimensions: core disgust, animal-reminder disgust, and contamination disgust. These items include 13 true/false items and 12 items that are rated on a 3-point scale (0, 0.5, and 1$)$ with regards to the extent to which participants find the experience "Not Disgusting At All, Slightly Disgusting, or Very Disgusting”. The DS-R has demonstrated a high degree of internal consistency, and adequate convergent and discriminant validity (Olatunji et al., 2007). The DS-R had an Alpha coefficient of 0.77 in the present study. The DS-R-Persian has an excellent internal consistency (Cronbach's a $=0.87)$ and test-retest reliability $(r=0.85)$ assessed in Iranian student sample (Shams, Foroughi, Moretz, \& Olatunji, 2013). Confirmatory factor analysis found support for two- and three-factor models of the PDS-R. An examination of the internal consistency estimates suggests that a two-factor model of contagion disgust and animal-reminder disgust may be more parsimonious. Structural equation modeling also revealed that latent disgust sensitivity, defined by the contagion disgust and animal-reminder disgust subscales of the PDS-R, was significantly associated with latent symptoms of contamination and non-contamination-based OCD when controlling for latent negative affect (Shams et al., 2013).

2) The Obsessive-Compulsive Inventory-Revised (OCI-R; Foa et al., 2002). The OCI-R is a 18-item questionnaire based on the earlier 84-item OCI (Foa, Kozak, Salkovskis, Coles, \& Amir, 1998). Participants rate the degree to what extent they have been bothered or distressed by OCD symptoms in the past month on a 5-point scale starting from 0 (not at all) to 4 (extremely). The OCI-R assesses OCD symptoms across six factors: washing, checking, ordering, obsessing, hoarding, and neutralizing. Preliminary data suggest that the OCI-R possesses a good internal consistency for the total score ( $\alpha$ 's ranged from 0.81 to 0.93 across samples), even though the internal consistency was weaker for certain subscales in non-clinical participants ( 0.34 for mental neutralizing and 0.65 for checking). Test-retest reliability was adequate ( 0.57 to 0.91 across samples). A cutoff of 15 on the CI-R showed good sensitivity (84\%) and specificity (78\%) in its ability to distinguish individuals with OCD from non-clinical participants (Foa et al., 2002). The OCI-R-Persian has an excellent internal consistency (Cronbach's a = 0.85) and test-retest reliability $(r=0.75)$ assessed in an Iranian student sample (Ghassemzadeh, 2011).

3) The Padua inventory-Washington State University revision (PI-WSUR; Burns et al., 1996). The PI-WSUR is a 39-item questionnaire that assesses the severity of OCD symptoms. The inventory consists of five subscales, including checking, contamination/washing, harm-obsession, harm-impulse, and grooming. The complete PI has adequate psychometric properties and the contamination subscale has a high internal consistency $($ alpha $=0.085)$. The PI contamination subscale correlates highly with other measures of contamination fear (Burns et al., 1996). The PI-WSUR-Persian has an excellent internal consistency (Cronbach's a $=0.92$ ) and testretest reliability $(r=0.77)$ assessed in an Iranian students sample (Shams, Kaviani, Esmaili, Ebrahimkhani, \& Amin Manesh, 2011). 


\subsection{Statistical Analysis}

Frequencies (percentages) were used to summarize qualitative variables. Continuous variables are presented as mean (standard deviation) or median (25th and 75th percentiles). Relation between DS-R score and demographic characteristics were investigated using Student's t-test, Mann-Whitney U test, one-way analysis of variance (ANOVA) and Kruskal-Wallis test. We also used Tukey post hoc test when the ANOVA showed significant differences between groups. Statistical analyses were performed using the statistical package SPSS version 20 for Windows (SPSS Inc, Chicago, IL, USA). All tests were two-tailed and p-values less than 0.05 were considered significant.

\section{Results}

Forty four women $(73.3 \%)$ and 16 men $(26.7 \%)$ participated in the study (mean age $=30.46$ years, SD $=8.09$ ). The demographic characteristics of the participants are presented in Table 1. Age groups were arranged using quartiles and the percentages of participants in each group arealso reported in Table 1 (ages values were missing for 4 participants).

Table 2 shows the correlations between the DS-R and the OCD scales (OCI-R and PI-WSUR). The DS-R total score $(0.264)$ and the core $(0.254)$ and contamination $(0.314)$ subscales scores were associated with OCI-R total score. DS-R total score also correlated with OCI-R checking (0.272) and washing subscales (0.284), and total and subscales showed rather high correlations with PI-WSUR total and subscales scores. DS-R total score correlated with PI-WSUR total score (0.307) and with the contamination obsessions and washing compulsions subscale (0.336). DS-R core subscale highly correlated with PI-WSUR total score (0.362) and the following subscales: contamination obsessions and washing compulsions (0.285), checking compulsions (0.347) and

Table 1. Demographic characteristics of the participants.

\begin{tabular}{|c|c|c|c|}
\hline \multicolumn{2}{|c|}{ Characteristics } & \multirow{2}{*}{$\begin{array}{c}\text { Frequency } \\
16\end{array}$} & \multirow{2}{*}{$\begin{array}{c}\text { Percentage } \\
26.7\end{array}$} \\
\hline Sex & Men & & \\
\hline & Women & 44 & 73.3 \\
\hline \multirow[t]{4}{*}{ Age } & $<25$ & 13 & 23.2 \\
\hline & $>=25 \&<29$ & 13 & 23.2 \\
\hline & $>=29 \&<34$ & 13 & 23.2 \\
\hline & $>=34$ & 17 & 30.4 \\
\hline \multirow[t]{3}{*}{ Marital status } & Single & 23 & 38.3 \\
\hline & Married & 33 & 55 \\
\hline & Divorced & 4 & 6.7 \\
\hline \multirow[t]{3}{*}{ Education } & Undergraduate & 8 & 13.3 \\
\hline & Graduate & 35 & 58.3 \\
\hline & Post graduate & 17 & 28.4 \\
\hline \multirow[t]{2}{*}{ Economic status } & Inappropriate & 8 & 13.8 \\
\hline & Appropriate & 50 & 86.2 \\
\hline \multirow[t]{4}{*}{ Occupation } & Student & 8 & 13.6 \\
\hline & Employed & 11 & 18.6 \\
\hline & Unemployed & 15 & 25.4 \\
\hline & Housekeeper & 25 & 42.4 \\
\hline Religion & Muslim & 60 & 100 \\
\hline
\end{tabular}


Table 2. Correlations between DS-R and OCI-R and DS-R and PI-WSUR.

\begin{tabular}{|c|c|c|c|c|}
\hline & $\begin{array}{l}\text { DS-R core } \\
\text { r ( } p \text {-value) }\end{array}$ & $\begin{array}{l}\text { DS-R animal reminder } \\
\mathrm{r} \text { ( } p \text {-value })\end{array}$ & $\begin{array}{l}\text { DS-R contamination } \\
\mathrm{r}(p \text {-value })\end{array}$ & $\begin{array}{l}\text { DS-R total } \\
\text { r ( } p \text {-value })\end{array}$ \\
\hline \multirow[t]{2}{*}{ OCI-R checking } & 0.322 & 0.095 & 0.249 & 0.272 \\
\hline & $\left(0.012^{*}\right)$ & $(0.471)$ & $(0.555)$ & $\left(0.036^{*}\right)$ \\
\hline \multirow[t]{2}{*}{ OCI-R hoarding } & 0.205 & 0.015 & 0.221 & 0.170 \\
\hline & $(0.116)$ & $(0.908)$ & $(0.090)$ & $(0.194)$ \\
\hline \multirow[t]{2}{*}{ OCI-R neutralization. } & 0.121 & 0.023 & 0.166 & 0.116 \\
\hline & $(0.356)$ & $(0.864)$ & $(0.204)$ & $(0.380)$ \\
\hline \multirow[t]{2}{*}{ OCI-R obsessing } & 0.239 & 0.046 & 0.091 & 0.167 \\
\hline & $(0.066)$ & $(0.725)$ & $(0.489)$ & $(0.201)$ \\
\hline \multirow[t]{2}{*}{ OCI-R ordering } & 0.235 & -0.024 & 0.061 & 0.128 \\
\hline & $(0.070)$ & $(0.855)$ & $(0.646)$ & $(0.329)$ \\
\hline \multirow[t]{2}{*}{ OCI-R washing } & 0.239 & 0.192 & 0.310 & 0.284 \\
\hline & $(0.066)$ & $(0.142)$ & $\left(0.016^{*}\right)$ & $\left(0.028^{*}\right)$ \\
\hline \multirow[t]{2}{*}{ OCI-R TOTAL } & 0.314 & 0.083 & 0.254 & 0.264 \\
\hline & $\left(0.014^{*}\right)$ & $(0.527)$ & $\left(0.049^{*}\right)$ & $\left(0.041^{*}\right)$ \\
\hline PI-WSUR & 0.285 & 0.214 & 0.380 & 0.336 \\
\hline Contamination obsessions and washing compulsions & $\left(0.027^{*}\right)$ & $(0.101)$ & $\left(0.003^{* *}\right)$ & $\left(0.009^{* *}\right)$ \\
\hline PI-WSUR. & 0.170 & 0.020 & 0.091 & 0.121 \\
\hline Dressing/grooming compulsions & $(0.193)$ & $(0.877)$ & $(0.488)$ & $(0.358)$ \\
\hline PI-WSUR & 0.347 & 0.083 & 0.250 & 0.280 \\
\hline Checking compulsions & $\left(0.007^{* *}\right)$ & $(0.527)$ & $(0.054)$ & $\left(0.030^{*}\right)$ \\
\hline PI-WSUR & 0.345 & 0.057 & 0.173 & 0.248 \\
\hline Obsessive thoughts of harm to self/others & $\left(0.007^{* *}\right)$ & $(0.667)$ & $(0.185)$ & $(0.056)$ \\
\hline PI-WSUR & 0.083 & -0.149 & -0.095 & -0.043 \\
\hline Obsessive impulses of harm to self/others & $(0.528)$ & $(0.257)$ & $(0.470)$ & $(0.741)$ \\
\hline PI-WSUR & 0.362 & 0.107 & 0.284 & 0.307 \\
\hline TOTAL & $\left(0.004^{* *}\right)$ & $(0.416)$ & $\left(0.028^{*}\right)$ & $\left(0.017^{*}\right)$ \\
\hline
\end{tabular}

Note: Pearson correlation coefficient $=\mathrm{r}$, DS-R $=$ Disgust scale revised, OCI-R = Obsessive-Compulsive Inventory-Revised, PI-WSUR = Padua inventory Washington state university revision. $p$-value $<0.05,{ }^{* *} p$-value $<0.01$.

obsessive thoughts of harm to self/others (0.345). DS-R contamination subscale also correlated highly with the PI-WSUR contamination obsessions and washing compulsions subscale (0.380).

Tables 3-6 show the distribution of DS total and subscales scores based on demographic characteristics. Women's mean DS total score was significantly higher than men's mean DS total score $(p=0.003)$ and the mean of scores was significantly different between women and men for all subscales. Married patients had a significantly higher average score too. There was a statistically significant difference $(p=0.017)$ between means of DS total scores in occupation groups. Based on the results of Tukey post hoc test, this difference was due to the discrepancy between the students and housekeepers groups' means of DS total score $(p=0.009)$. 
Table 3. Distribution of DS-R total scores based on demographic characteristics.

\begin{tabular}{|c|c|c|c|c|c|}
\hline & & Characteristics & Counts & Mean/Median & SD/IQR \\
\hline \multirow[t]{2}{*}{ Sex } & Men & 16 & 51.13 & 14.38 & $\mathrm{~T} 0.003^{* *}$ \\
\hline & Women & 44 & 63.98 & 14.26 & \\
\hline \multirow[t]{4}{*}{ Age } & $<25$ & 13 & 54.92 & 16.78 & A0.330 \\
\hline & $>=25 \&<29$ & 13 & 59.77 & 9.64 & \\
\hline & $>=29 \&<34$ & 13 & 59.31 & 16.992 & \\
\hline & $>=34$ & 17 & 65.59 & 17.48 & \\
\hline \multirow[t]{3}{*}{ Marital status } & Single & 23 & 57 & $(49.00-62.00)$ & $\mathrm{K} 0.002^{* *}$ \\
\hline & Married & 33 & 67 & $(60.00-77.00)$ & \\
\hline & Divorced & 4 & 45 & $(31.75-57.50)$ & \\
\hline \multirow[t]{3}{*}{ Education } & Undergraduate & 8 & 59.13 & 16.28 & A0.564 \\
\hline & Graduate & 35 & 62.31 & 13.73 & \\
\hline & Post graduate & 17 & 57.39 & 18.11 & \\
\hline \multirow[t]{2}{*}{ Economic status } & Inappropriate & 50 & 61.5 & $(49.00,68.50)$ & M0.397 \\
\hline & Appropriate & 8 & 62 & $(56.25,77.75)$ & \\
\hline \multirow[t]{4}{*}{ Occupation } & Student & 8 & & 16.52 & A0.017 \\
\hline & Employed & 11 & & 17.78 & \\
\hline & Unemployed & 15 & & 9.54 & \\
\hline & Housekeeper & 25 & & 14.62 & \\
\hline
\end{tabular}

Note: DS-R $=$ Disgust scale revised, $\mathrm{SD}=$ Standard deviation, IQR $=$ Interquartile range. ${ }^{*} p$-value $<0.05,{ }^{* *} p$-value $<0.01$. Significances are based on Student's t-test (T), One-way analysis of variance (A), Kruskal-Wallis test (K) and Mann-Whitney U test (M).

Table 4. Distribution of DS-R core subscale scores based on demographic characteristics.

\begin{tabular}{|c|c|c|c|c|c|}
\hline & & Characteristics & Counts & Mean/Median & $\mathrm{SD} / \mathrm{IQR}$ \\
\hline \multirow[t]{2}{*}{ Sex } & Men & 16 & 24.69 & 7.76 & T0.034* \\
\hline & Women & 44 & 29.59 & 7.71 & \\
\hline \multirow[t]{4}{*}{ Age } & $<25$ & 13 & 26.15 & 8.26 & A0.439 \\
\hline & $>=25 \&<29$ & 13 & 28.46 & 6.46 & \\
\hline & $>=29 \&<34$ & 13 & 26.69 & 9.34 & \\
\hline & $>=34$ & 17 & 30.65 & 8.507 & \\
\hline \multirow[t]{3}{*}{ Marital status } & Single & 23 & 27.00 & $(20.00-30.00)$ & K0.006 \\
\hline & Married & 33 & 31.00 & $(28.00-37.00)$ & \\
\hline & Divorced & 4 & 18.50 & $(15.50-28.25)$ & \\
\hline \multirow[t]{3}{*}{ Education } & Undergraduate & 8 & 29.88 & 7.34 & A0.153 \\
\hline & Graduate & 35 & 29.46 & 7.47 & \\
\hline & Post graduate & 17 & 25.12 & 8.77 & \\
\hline \multirow[t]{2}{*}{ Economic status } & Inappropriate & 50 & 28.50 & $(23.00,33.00)$ & M0.240 \\
\hline & Appropriate & 8 & 31.00 & $(27.50,33.50)$ & \\
\hline \multirow[t]{4}{*}{ Occupation } & Student & 8 & 22.13 & 8.89 & A0.013 \\
\hline & Employed & 11 & 27.09 & 8.36 & \\
\hline & Unemployed & 15 & 26.67 & 6.45 & \\
\hline & Housekeeper & 25 & 31.76 & 7.21 & \\
\hline
\end{tabular}

Note: DS-R = Disgust scale revised, $\mathrm{SD}=$ Standard deviation, IQR $=$ Interquartile range. ${ }^{*}$-value $<0.05,{ }^{* *} p$-value $<0.01$. Significances are based on Student's t-test (T), One-way analysis of variance (A), Kruskal-Wallis test (K) and Mann-Whitney U test (M). 
Table 5. Distribution of DS-R animal reminder subscale scores based on demographic characteristics.

\begin{tabular}{|c|c|c|c|c|c|}
\hline & & Characteristics & Counts & Mean/Median & $\mathrm{SD} / \mathrm{IQR}$ \\
\hline \multirow[t]{2}{*}{ Sex } & Men & 16 & 16.38 & 6.02 & T0.006 ${ }^{* *}$ \\
\hline & Women & 44 & 21.43 & 6.06 & \\
\hline \multirow[t]{4}{*}{ Age } & $<25$ & 13 & 17.54 & 8.75 & A0.448 \\
\hline & $>=25 \&<29$ & 13 & 19.92 & 5.07 & \\
\hline & $>=29 \&<34$ & 13 & 20.39 & 6.16 & \\
\hline & $>=34$ & 17 & 21.47 & 6.012 & \\
\hline \multirow[t]{3}{*}{ Marital status } & Single & 23 & 21.00 & $(15.00-24.00)$ & K0.099 \\
\hline & Married & 33 & 22.00 & $(18.50-26.00)$ & \\
\hline & Divorced & 4 & 15.50 & $(10.00-20.25)$ & \\
\hline \multirow[t]{3}{*}{ Education } & Undergraduate & 8 & 18.50 & 5.53 & A0.729 \\
\hline & Graduate & 35 & 20.14 & 6.48 & \\
\hline & Post graduate & 17 & 20.70 & 6.87 & \\
\hline \multirow[t]{2}{*}{ Economic status } & Inappropriate & 50 & 21.00 & $(15.00,25.00)$ & M0.726 \\
\hline & Appropriate & 8 & 20.50 & $(17.00,27.25)$ & \\
\hline \multirow[t]{4}{*}{ Occupation } & Student & 8 & 14.87 & 8.46 & A0.101 \\
\hline & Employed & 11 & 20.00 & 7.65 & \\
\hline & Unemployed & 15 & 21.13 & 4.88 & \\
\hline & Housekeeper & 25 & 21.04 & 5.55 & \\
\hline
\end{tabular}

Note: DS-R = Disgust scale revised, $\mathrm{SD}=$ Standard deviation, $\mathrm{IQR}=$ Interquartile range. ${ }^{*}$-value $<0.05,{ }^{* *} p$-value $<0.01$. Significances are based on Student's t-test (T), One-way analysis of variance (A), Kruskal-Wallis test (K) and Mann-Whitney U test (M).

Table 6. Distribution of DS-R contamination subscale scores based on demographic characteristics.

\begin{tabular}{|c|c|c|c|c|c|}
\hline & & Characteristics & Counts & Mean/Median & $\mathrm{SD} / \mathrm{IQR}$ \\
\hline \multirow[t]{2}{*}{ Sex } & Men & 16 & 10.06 & 3.27 & T0.010* \\
\hline & Women & 44 & 12.95 & 3.89 & \\
\hline \multirow[t]{4}{*}{ Age } & $<25$ & 13 & 11.23 & 3.61 & A0.412 \\
\hline & $>=25 \&<29$ & 13 & 11.38 & 3.45 & \\
\hline & $>=29 \&<34$ & 13 & 12.23 & 4.21 & \\
\hline & $>=34$ & 17 & 13.47 & 4.66 & \\
\hline \multirow[t]{3}{*}{ Marital status } & Single & 23 & 12.00 & $(9.00-13.00)$ & K0.026* \\
\hline & Married & 33 & 14.00 & $(10.50-16.00)$ & \\
\hline & Divorced & 4 & 8.00 & $(4.00-14.25)$ & \\
\hline \multirow[t]{3}{*}{ Education } & Undergraduate & 8 & 10.75 & 4.17 & A0.394 \\
\hline & Graduate & 35 & 12.71 & 3.63 & \\
\hline & Post graduate & 17 & 11.76 & 4.42 & \\
\hline \multirow[t]{2}{*}{ Economic status } & Inappropriate & 50 & 13.00 & $(9.75,15.00)$ & M0.490 \\
\hline & Appropriate & 8 & 13.00 & $(10.25,16.75)$ & \\
\hline \multirow[t]{4}{*}{ Occupation } & Student & 8 & 9.75 & 4.37 & A0.183 \\
\hline & Employed & 11 & 12.18 & 4.42 & \\
\hline & Unemployed & 15 & 11.73 & 2.37 & \\
\hline & Housekeeper & 25 & 13.20 & 4.21 & \\
\hline
\end{tabular}

Note: DS-R = Disgust scale revised, $\mathrm{SD}=$ Standard deviation, IQR $=$ Interquartile range. ${ }^{*}$-value $<0.05,{ }^{* *} p$-value $<0.01$. Significances are based on Student's t-test (T), One-way analysis of variance (A), Kruskal-Wallis test (K) and Mann-Whitney U test (M). 


\section{Discussion}

The nature of disgust is quite varied in Western cultures. Culture seems to play a role in psychopathology. Reviews on eastern cultural matters are imperative to reach comprehensive understanding of the question. Iranian population, which is rooted in Persian culture, has a different socio-cultural background than Western countries, which may influence the construct of disgust emotion. The present study represents a first attempt to broaden previous research and to explore the role of disgust emotion and OCD in Iranian OC patients. The hypothesis was that disgust emotion is substantially related to certain OC subscales of symptoms associated with OCD (e.g. washing or checking subscale) but not to all of them. Thus, the main aim was to find out the relationship of disgust emotion with OCD, and to answer the question "Which domains of disgust sensitivity are related to which kinds of OCD symptoms?"

The major results can be summarized as follows: correlations between the disgust (DS-R) and the obsessive-compulsive disorder scales (OCI-R and PI-WSUR) indicated that DS-R total score and its core and contamination disgust subscales were associated with OCI-R total as well as PI-WSUR total scores, but these relationships were not found in DS-R animal reminder. DS-R total score is also correlated with washing and checking subscales in OCI-R together with contamination obsessions and washing and checking compulsions in PI-WSUR. DS-R core subscale is highly related with the PI-WSUR total score and the following subscales: contamination obsessions and washing compulsions, checking compulsions and obsessive thoughts of harm to self/others. DS-R contamination subscale is also highly correlated with the PI-WSUR total and PI-WSUR contamination obsessions and washing compulsions subscales. The washing-related OCD symptoms showed the clearest relationship with disgust total and its subscales (core, contamination). Other OCD symptom domains (checking and obsessive thoughts of harm to self/others) were correlated with DS-R core. However, when we examined each disgust sensitivity subscale with every other OCI-R and PI-WSU-R subscales, the clearest relationship was found for the OCI-R washing and checking and the following subscales of the PI-WSU-R: contamination obsession and washing compulsion, checking and obsessive thoughts of harm to self/others. Thus, the elevated disgust sensitivity seen in those with washing, checking and obsessive thoughts of harm to self/others is most likely an artifact of OC symptoms. These kinds of findings could indicate that the primary function of disgust is to protect oneself from various forms of contamination (Matchett \& Davey, 1991; Woody \& Tolin, 2002). OCD patients with hoarding neutralization, ordering dressing/grooming compulsion or obsessive impulse of harm to self/others did not report feelings of disgust. Evidence for the relationship of disgust sensitivity to OCD, however, has been mixed. OCD symptoms, particularly washing and checking, was associated with DS-R core and DS-R contamination. The core disgust is based on the sense of offensiveness and the threat of disease, such as rotten food, small animals, and body waste products (Olatunji et al, 2007; Rozin, Taylor, Ross, Bennett, \& Hejmadi, 2005) and contamination disgust is related to the perceived threat of interpersonal transmission of bodily fluids or microbes (Olatunji et al, 2007; Rozin, Haidt, \& McCauley, 2008). However similar results were not found for DS-R animal reminder. This subscale reflects the aversion to stimuli that serves as a reminder of the animal origins of humans such as death and body envelope violations (Olatunji et al, 2007; Rozin et al., 2008).

Overall, the present results suggest a relationship between certain OCD subscales and disgust sensitivity and this pattern of findings points out to the possibility that DS-R core and DS-R contamination disgust are somehow involved in OCD. This finding is consistent with previous researches describing OC symptoms and disgust measures. The etiology and maintenance of OCD-related contamination obsessions and washing compulsions was a prominent role for disgust sensitivity (Olatunji et al., 2004; Schienle et al., 2003). Numerous stronger associations between disgust proneness and OCD symptoms are commonly observed together with the contamination subtype (Tolin et al., 2006) and other studies have underlined the importance of its role in the etiology and maintenance of the disorder (Olatunji et al., 2010; Mancini et al., 2001; Rozin et al., 2005). Some further studies have also found significant positive associations between disgust proneness and a range of OCD symptoms, for example positive associations between self-report measures of disgust and OCD-related contamination concerns (Moretz \& McKay, 2008; Olatunji et al., 2010; Sawchuk et al., 2000); positive relationships with all four of the MOCI subscales washing, checking, doubting and slowness, (Schienle et al., 2003) and association with the washing subscale of the MOCI (Muris et al., 2000); an increased severity of OCD with contamination fears symptomatology (Cisler et al., 2008; Mancini et al., 2001; Olatunji et al., 2010; Rachman, 2004; Tolin et al., 2006); or with hoarding, neutralizing, and ordering symptoms of OCD (Olatunji et al., 2010). Disgust also sig- 
nificantly predicts obsessive-compulsive washing even when controlling for anxiety and depression (Moretz et al., 2008, Mancini et al., 2001; Olatunji et al., 2010, Thorpe et al., 2003).

In the present study, the relationship between disgust sensitivity and OCD symptoms was proved to some extent, although the DS-R animal reminder correlations remained insignificant. Despite promising results, the association between symptoms of disgust sensitivity and contamination based OCD has not been a consistent finding. Similar to the present results, less robust outcomes were reported by Tolin et al. (2006), who found that only disgust-specific hygienic concerns retained its relationship with OCD washing and hoarding might be associated with reduced disgust-sensitivity. In fact, hoarding may be expected to show a negative correlation with measures of disgust (Schienle et al., 2003) or no relation between individual differences in OCD tendencies and the ability to detect disgust (Rozin et al., 2005). The association between disgust and OCD symptoms became also non-significant, when controlling for trait anxiety, in a nonclinical sample (Muris, Merckelbach, Schmidt, \& Tierney, 1999).

Disgust partially explains the ethnic differences observed in contamination concerns, as relative to European American participants, African Americans who significantly scored higher on the Disgust Scale (Haidt et al., 1994), and nonwhites (mostly African Americans) who also scored significantly higher than whites on the Disgust Scale. On the MOCI washing subscale, African American participants' scores were higher than those of European American participants, although they did not have more severe OC symptoms (Thomas, Turkheimer, \& Oltmanns, 2007). Bodily waste or secretions, which is described as a feeling of "Nejasat" or "spiritual impurity" in the Iranian culture (Dadfar, Bolhari, Malakouti, \& Bayan Zadeh, 2001); showed a high frequency of obsessions with themes of fear of impurity (62\%) in sample with OCD in Iran. In this population, while the rituals revolve around contamination and cleaning themes, they are tangled with issues of religious contamination and purity, which usually manifest itself as a fear of spiritual impurity (Ghassemzadeh et al., 2002). Clinical and anecdotal evidences from Iran suggest that contamination fears in patients with OCD are largely related to feelings of 'spiritual impurity' rather than distress about germs, dirt or any other contamination sources that may cause disease or harm. The role of disgust in religious-based contamination fears needs to be investigated further in the non-western and Islamic culture of Iran. Therefore the experience of disgust and its relationship with OCD symptoms may be shaped by the broader cultural such as schematic themes and rules advised by religion. While there is a growing interest in exploring the role of disgust in psychopathology, particularly in relation to OCD, there is a big gap in the literature on cross-cultural studies in both clinical and non-clinical samples (Shams et al., 2013). However, the scarcity of focused research in this area makes it difficult to come to any conclusions.

The relationship between disgust sensitivity with demographics like age, sex, marital status, education, socio-economic and occupation was another aim. The results indicated that patients with OCD complaints were characterized by relatively high levels of disgust sensitivity in women, married patients and occupation groups. The results on the distribution of DS-R total and subscale scores based on demographic characteristics showed that the rate of disgust in total as well as in core, contamination and animal reminder was significantly higher in women than men. Married patients had significantly higher average scores too. There was also a difference between means of DS-R total score in occupation groups and this difference was statistically significant. Nonetheless, we predicted that women would exhibit higher disgust sensitivity. The current study's results replicate the finding that women have higher mean levels of disgust than do men. The heightened disgust sensitivity in women suffering from OCD appeared not restricted to core disgust elicitors but was similarly enhanced for elicitors from the animal-reminder, contamination domain and finally DS-R -Total. These findings are consistent with previous researches (Curtis, Aunger, \& Rabie, 2004; Haidt et al., 1994; Labad et al., 2008; Mancini et al., 2001; Olatunji et al., 2005; Rachman, 2004) which indicated that women exhibited significantly higher disgust sensitivity than men. Higher levels of disgust sensitivity among women may partially explain their increased vulnerability to OCD. Similar results found disgust sensitivity mediates the gender differences in several anxiety disorders including blood-injection-injury phobia (Connolly, Olatunji, \& Lohr, 2008; Olatunji et al., 2005) and spider phobia (Connolly et al., 2008).

\section{Limitation}

A limitation of the present study was relying on use of self-reports measures. Indeed, self-report (Olatunj et al., 2004) and behavioral (Tsao \& McKay, 2004) studies have found robust associations between disgust proneness 
and contamination. But, in future research, OCD measures like obsessive beliefs questionnaire (OBQ-44), International Intrusive Thoughts Interview Schedule (IITIS), or Y-Box is also suggested. Another limitation in the present research was the use of a sample of OCD patientsonly. For a better understanding of the relationship between these two variables, it would be preferable to compare OCD with other anxiety and depression disorders.

In conclusion, the present research has found associations between OC symptoms and disgust emotion in an OCD sample. Our results also suggest that although this view of the association between OC symptom and disgust emotion has received some preliminary support in western countries, this association is yet to be examined in other eastern cultures. In summary, although symptom presentation, risk factors, and outcomes may vary cross-culturally, very little is known about disgust emotion in Iranian and eastern culture. Additional work is needed to better understand these symptoms in other culture. To conclude, the present study provided empirical support for the idea that disgust sensitivity is somehow involved in the generation of OCD complaints.

\section{References}

American Psychiatric Association (2000). Diagnostic and Statistical Manual of Mental Disorders (4th ed., Text Rev.). Washington DC: Author.

Burns, G. L., Keortge, S. G., Formea, G. M., \& Sternberger, L. G. (1996). Revision of the Padua Inventory of Obsessive Compulsive Disorder Symptoms: Distinctiveness between Worry, Obsessions, and Compulsions. Behaviour Research and Therapy, 34, 163-173. http://dx.doi.org/10.1016/0005-7967(95)00035-6

Cisler, J. M., Olatunji, B. O., Sawchuk, C. N., \& Lohr, J. M. (2008). Specificity of Emotional Maintenance Processes among Contamination Fears and Blood-Injection-Injury Fears. Journal of Anxiety Disorders, 22, 915-923.

http://dx.doi.org/10.1016/j.janxdis.2007.09.006

Connolly, K. M., Olatunji, B. O, \& Lohr, J. M. (2008). Evidence for Disgust Sensitivity Mediating the Sex Differences Found in Blood-Injection Injury Phobia and Spider Phobia. Personal and Individual Differences, 44, 898-908. http://dx.doi.org/10.1016/i.paid.2007.10.020

Curtis, V., Aunger, R., \& Rabie, T. (2004). Evidence That Disgust Evolved to Protect from Risk of Disease. Proceedings of the Royal Society Biological Sciences, 271, 131-133. http://dx.doi.org/10.1098/rsbl.2003.0144

Dadfar, M., Bolhari, J., Malakouti, K., \& Bayan Zadeh, A. (2001). An Examination of the Phenomenology of Obsessive-Compulsive Disorder. The Quarterly Journal of Andisheh VaRaftar, 7, $27-32$.

Foa, E. B., Huppert, J. D., Leiberg, S., Langner, R., Kichic, R., Hajcak, G., et al. (2002). The Obsessive-Compulsive Inventory: Development and Validation of a Short Version. Psychological Assessment, 14, 485-496. http://dx.doi.org/10.1037/1040-3590.14.4.485

Foa, E. B., Kozak, M. J., Salkovskis, P. M., Coles, M. E., \& Amir, N. (1998). The Validation of a New Obsessive Compulsive Disorder Scale: The Obsessive Compulsive Inventory. Psychological Assessment, 10, 206-214. http://dx.doi.org/10.1037/1040-3590.10.3.206

Ghassemzadeh, H., Mojtabai, R., Khamseh, A., Ebrahimkhani, N., Issazadegan, A., \& Saif-Nobakht, Z. (2002). Symptoms of Obsessive-Compulsive Disorder in a Sample of Iranian Patients. International Journal of Social Psychiatry, 48, 220228. http://dx.doi.org/10.1177/002076402128783055

Ghassemzadeh, H., Shams, G., Jamal, A., Karamghadiri, N., Ebrahimkhani, N., \& Rajabloo, M. (2011). Psychometric Properties of a Persian-Language Version of the Obsessive-Compulsive Inventory-Revised: OCI-R-Persian. Psychology, 2, 210-215. http://dx.doi.org/10.4236/psych.2011.23032

Haidt, J., McCauley, C., \& Rozin, P. (1994). Individual Differences in Sensitivity to Disgust: A Scale Sampling Seven Domains of Disgust Elicitors. Personality and Individual Differences, 16, 701-713. http://dx.doi.org/10.1016/0191-8869(94)90212-7

Izard, C. E. (1993). Organizational and Motivational Functions of Discrete Emotions. In M. Lewis, J. M. Haviland-Jones, \& L. F. Barret (Eds.), Handbook of Emotions (pp. 631-641). New York: Guilford Press.

Labad, J., Menchon, J. M., Alonso, P., Segalas, C., Jimenez, S., \& Jaurrieta, N. (2008). Gender Differences in ObsessiveCompulsive Symptom Dimensions. Depression and Anxiety, 25, 832-838. http://dx.doi.org/10.1002/da.20332

Mancini, F., Gragnani, A., \& D’Olimpio, F. (2001). The Connection between Disgust and Obsessions and Compulsions in a Non-Clinical Sample. Personality and Individual Differences, 31, 1173-1180. http://dx.doi.org/10.1016/S0191-8869(00)00215-4

Matchett, G., \& Davey, G. C. (1991). A Test of the Disease Avoidance Model of Animal Phobias. Behaviour Research and Therapy, 29, 91-94. http://dx.doi.org/10.1016/S0005-7967(09)80011-9

Moretz, M. W., \& McKay, D. (2008). Disgust Sensitivity as a Predictor of Obsessive-Compulsive Contamination Symptoms and Associated Cognitions. Journal of Anxiety Disorders, 22, 707-715. http://dx.doi.org/10.1016/j.janxdis.2007.07.004 
Muris, P., Merckelbach, H., Nederkoorn, S., Rassin, E., Candel, I., \& Horselenberg, R. (2000). Disgust and Psychopathological Symptoms in a Nonclinical Sample. Personality and Individual Differences, 29, 1163-1167. http://dx.doi.org/10.1016/S0191-8869(99)00263-9

Muris, P., Merckelbach, H., Schmidt, H., \& Tierney, S. (1999). Disgust Sensitivity, Trait Anxiety and Anxiety Disorders Symptoms in Normal Children. Behaviour Research and Therapy, 37, 953-961. http://dx.doi.org/10.1016/S0005-7967(99)00045-5

Olatunji, B. O., Cisler, J. M., McKay, D., \& Phillips, M. (2010). Is Disgust Associated with Psychopathology? Emerging Research in the Anxiety Disorders. Psychiatry Research, 175, 1-10. http://dx.doi.org/10.1016/j.psychres.2009.04.007

Olatunji, B. O., Moretz, M., Wolitzky-Taylor, K. B., McKay, D., McGrath, P., \& Ciesielski, B. (2010). Disgust Vulnerability and Symptoms of Contamination-Based OCD: Descriptive Tests of Incremental Specificity. Behavior Therapy, 42, 475490. http://dx.doi.org/10.1016/j.beth.2009.11.005

Olatunji, B. O., Sawchuk, C. N., Arrindel, W. A., \& Lohr, J. M. (2005). Disgust Sensitivity as a Mediator of the Sex Differences in Contamination Fears. Personality and Individual Differences, 38, 713-722. http://dx.doi.org/10.1016/j.paid.2004.05.025

Olatunji, B. O., Sawchuk, C. N., Lohr, J. M., \& de Jong, P. J. (2004). Disgust Domains in the Prediction of Contamination Fear. Behaviour Research Therapy, 42, 93-104. http://dx.doi.org/10.1016/S0005-7967(03)00102-5

Olatunji, B. O., Williams, N. L., Tolin, D. F., Sawchuk, C. N., Abramowitz J. S., \& Lohr, J. M. (2007). The Disgust Scale: Item Analysis, Factor Structure, and Suggestions for Refinement. Psychological Assessment, 19, 281-297. http://dx.doi.org/10.1037/1040-3590.19.3.281

Phillips, M. L., Senior, C., Fahy, T., \& David, A. S. (1998). Disgust-The Forgotten Emotion of Psychiatry. British Journal of Psychiatry, 172, 373-375. http://dx.doi.org/10.1192/bjp.172.5.373

Rachman, S. (2004). Fear of Contamination. Behaviour Research and Therapy, 42, 1227-1255. http://dx.doi.org/10.1016/j.brat.2003.10.009

Rasmussen, S. A., \& Eisen, J. L. (1992). The Epidemiology and Clinical Features of Obsessive Compulsive Disorder. Psychiatric Clinics of North America, 15, 743-758.

Rozin, P., Haidt, J., \& McCauley, C. R. (2008). Disgust. In M. Lewis, J. M. Haviland-Jones, \& L. F. Barret (Eds.), Handbook of Emotions (3rd ed., pp. 757-776). New York: Guilford Press.

Rozin, P., Taylor, C., Ross, L., Bennett, G., \& Hejmadi, A. (2005). General and Specific Emotion Recognition Abilities: Relations among Individual Differences in Recognition of Disgust and Other Emotional Expressions in Facial and Bodily Representations, Obsessive-Compulsive Tendencies, and Disgust Sensitivity. Cognition and Emotion, 19, 397-412. http://dx.doi.org/10.1080/02699930441000166

Sawchuk, C. N., Lohr, J. M., Tolin, D. F., Lee, T. C., \& Kleinknecht, R. A. (2000). Disgust Sensitivity and Contamination Fears in Spider and Blood-Injection-Injury Phobias. Behaviour Research and Therapy, 38, 753-762. http://dx.doi.org/10.1016/S0005-7967(99)00093-5

Schienle, A., Stark, R., Walter, B., \& Vaitl, D. (2003). The Connection between Disgust Sensitivity and Blood-Related Fears, Faintness Symptoms, and Obsessive Compulsiveness in a Non-Clinical Sample. Anxiety, Stress, and Coping, 16, $185-193$.

Shams, G., Foroughi, E., Moretz, M. W., \& Olatunji, B. O. (2013). Factor Structure and Psychometric Properties of the Persian Disgust Scale-Revised: Examination of Specificity to Symptoms of Obsessive-Compulsive Disorder. Psychology, 4, 526-534. http://dx.doi.org/10.4236/psych.2013.46075

Shams, G., Kaviani, H., Esmaili, Y., Ebrahimkhani, N., \& Amin Manesh, A. (2011). Psychometric Properties of the Persian Version of the Padua Inventory: Washington State University Revision (PI-WSUR). Iranian Journal of Psychiatry, 6, 12-18.

Thomas, J., Turkheimer, E., \& Oltmanns, T. F. (2007). Psychometric Analysis of Racial Differences on the Maudsley Obsessional Compulsive Inventory. Assessment, 7, 247-258. http://dx.doi.org/10.1177/107319110000700305

Thorpe, S. J., Patel, S. P., \& Simonds, L. M. (2003). The Relationship between Disgust Sensitivity, Anxiety, and Obsessions. Behaviour Research and Therapy, 41, 1397-1409. http://dx.doi.org/10.1016/S0005-7967(03)00058-5

Tolin, D. F., Woods, C. M., \& Abramowitz, J. S. (2006). Disgust Sensitivity and Obsessive-Compulsive Symptoms in a Nonclinical Sample. Journal of Behavior Therapy and Experimental Psychiatry, 37, 30-40. http://dx.doi.org/10.1016/j.jbtep.2005.09.003

Tsao, S. D., \& McKay, D. (2004). Behavioral Avoidance Tests and Disgust in Contamination Fears: Distinctions from Trait Anxiety. Behaviour Research and Therapy, 42, 207-216. http://dx.doi.org/10.1016/S0005-7967(03)00119-0

Woody, S. R., \& Tolin, D. F. (2002). The Relationship between Disgust Sensitivity and Avoidant Behavior: Studies of Clinical and Nonclinical Samples. Journal of Anxiety Disorders, 16, 543-559.

http://dx.doi.org/10.1016/S0887-6185(02)00173-1 